\title{
Klasifikasi Pelanggan Deposito Potensial menggunakan Ensembel Least Square Support Vector Machine
}

\author{
${ }^{1}$ Firman Aziz, ${ }^{2}$ Jeffry \\ ${ }^{1,2}$ Fakultas Matematika dan Ilmu Pengetahuan Alam \\ ${ }^{1,2}$ Universitas Pancasakti \\ Makassar, Indonesia \\ ${ }^{1}$ firman.aziz@unpacti.ac.id \\ ${ }^{2}$ jeffry@unpacti.ac.id
}

\begin{abstract}
Abstrak
Abstrak Jumlah data yang sangat banyak pada industri perbankan sangat susah dianalisis secara manual untuk mendapatkan suatu informasi yang berguna agar dapat menentukan suatu kebijakan. Oleh karena itu, penggunaan data mining diharapkan dapat memberikan kontribusi dalam mengolah data tersebut. Berbagai metode telah banyak digunakan untuk mengklasifikasi suatu data, salah satunya adalah metode support vector machine. Penelitian ini bertujuan untuk melakukan klasifikasi terhadap nasabah yang berpotensi berlangganan deposito pada bank marketing dataset. Fokus penelitian ini mengusulkan pengembangan dari metode support vector machine yaitu metode least square support vector machine kemudian di ensemble menggunakan boosting. Data yang akan diolah adalah bank marketing dataset. Hasil menunjukkan bahwa metode yang diusulkan yakni ensemble least square support vector machine lebih baik dibandingkan dengan metode lainnya dengan persentase tingkat accuracy, sensitivity, specivicity masing-masing adalah $95.15 \%, 92.93 \%, 97.61 \%$ dengan total rata-rata hasil klasifikasi sebesar $95.23 \%$.
\end{abstract}

Kata Kunci: SVM, LS-SVM, Ensemble, AdaBoost, Bank Marketing.

\begin{abstract}
Abstract The vast amount of data in the banking industry is very difficult to analyze manually to obtain useful information in order to determine a policy. Therefore, the use of data mining is expected to contribute in processing the data. Various methods have been widely used to classify data, one of which is the support vector machine method. This study aims to classify customers who have the potential to subscribe to deposits in the bank marketing dataset. The focus of this study proposes the development of the support vector machine method, which is the least square support vector machine method, then ensemble using boosting. The data to be processed is the bank marketing dataset. The results show that the proposed method that is ensemble least square support vector machine is better than other methods with a percentage of accuracy level of $95.15 \%$, sensitivity $92.93 \%$, specialization of $97.61 \%$. The average total classification results is $95.23 \%$.
\end{abstract}

Keyword: $\quad$ SVM, LS-SVM, Ensemble, AdaBoost, Bank Marketing. 


\section{Pendahuluan}

Istilah Business Intelligence saat ini sangat familiar dikalangan perusahaan yang digunakan untuk menganalisis data bisnis agar menghasilkan suatu informasi yang terdiri dari strategi dan teknologi (Dedic \& Stanier, 2016). Teknologi Business Intelligence memberikan suatu pandangan historis, terkini, dan prediksi kedepan suatu bisnisyang meliputi reporting, online analytical processing, analytics, data mining, process mining, complex event processing, business performance management, benchmarking, text mining, predictive analytics, dan prescriptive analytics. Teknologi Business Intelligence dapat menangani jumlah data skala besar untuk membantu mengidentifikasi, mengembangkan, dan menciptakan peluang bisnis strategis baru dengan tujuan memudahkan interpretasi data, mengidentifikasi peluang baru, dan menerapkan strategi yang efektif berdasarkan wawasan untuk memberikan keunggulan bisnis yang kompetitif dan memiliki stabilitas jangka Panjang (Rud, 2009).

Sektor perbankan mulai menerapkan teknologi Business Intelligence dengan mengolah informasi nasabah terutama pada bidang pemasaran. Secara umum pendekatan perbankan dalam memperkenalkan barang atau jasanya yaitu dengan iklan melalui televisi, radio, surat kabar, dan lain-lain atau dengan menargetkan nasabah secara khusus atau disebut dengan bank direct marketing (Moro et al., 2011). penerapan bank direct marketing dalam memperkenalkan suatu produk baik berupa barang maupun jasa kepada nasabah melalui telepon, email dan lain-lain dianggap sangat efektif dalam menggaet nasabah. Akan tetapi, banyak nasabah yang merasa terganggu sehingga menimbulkan penilaian negatif bagi bank serta biaya dan waktu yang dikeluarkan oleh telemarketer (Elsalamony \& Elsayad, 2013), (Elsalamony, 2014), (Vajiramedhin \& Suebsing, 2014). mengatasi permasalahan tersebut maka perlu dilakukan pengolahan data dengan melakukan klasifikasi untuk menemukan suatu informasi yang berfungsi untuk membantu menemukan nasabah potensial (Abbas, 2015). Dalam klasifikasi terdapat proses menganalisis satu set data dan menghasilkan seperangkat aturan pengelompokan yang dapat digunakan untuk mendapatkan informasi masa depan.

Penelitian (Zhuang et al., 2018) mengadopsi teknik data mining melalui SPSS Modeler untuk memprediksi perilaku langganan deposito berjangka pelanggan dan memahami fitur-fitur pelanggan untuk meningkatkan efektivitas dan keakuratan pemasaran bank. Penelitian ini terbatas hanya pada penarikan kesimpulan tanpa memiliki pengukuran kinerja dalam teknik data mining. Kemudian, penelitian (Parlar, 2017) menganalisis dua metode pemilihan fitur yaitu information gain dan Chi-square pada dataset bank direct marketing untuk mengetahui fitur-fitur yang berpengaruh. Hasil menunjukkan metode pemilihan fitur Information Gain dan Chi-square sangat dekat, meskipun keduanya berbeda untuk lima fitur teratas. Penelitian (Ruangthong \& Jaiyen, 2015) mengusulkan metode untuk menganalisis informasi asimetris menggunakan algoritma SMOTE dan Rotation Forest (PCA) -J48 untuk menyelesaikan klasifikasi set data yang tidak seimbang. dimana algoritma SMOTE digunakan untuk memodifikasi data dan meningkatkan akurasi prediksi. Hasil menunjukkan algoritma SMOTE secara efektif menyelesaikan ketidaksetaraan data dan Rotation Forest (PCA) -J48 dapat mencapai nilai akurasi dan spesifisitas tertinggi. Namun, Rotation Forest (PCA) -J48 memiliki sensitivitas yang tinggi. Penelitian (Grzonka et al., 2016) membandingkan beberapa metode seperti decision trees, bagging, boosting, and random forests untuk melakukan klasifikasi data direct marketing campaigns. Hasil menunjukkan bahwa faktor yang sangat penting untuk hasil yang diperoleh adalah keacakan sampel bootstrap yang 
digunakan untuk membangun model. Kemudian, Penelitian (Lawi et al., 2017) mengusulkan metode Support Mesin Vektor menggunakan algoritma Adaboost untuk mengklasifikasikan pelanggan potensial untuk pemasaran langsung. Hasil menunjukkan bahwa metode Support Mesin Vektor menggunakan algoritma Adaboost menghasilkan akurasi $95,07 \%$ dan sensitivitasnya 91,65\% lebih tinggi dari pendekatan SVM biasa. Penelitian ini berhasil mengatasi permasalahan keacakan sample bootstrap Tetapi penelitian ini masih terbatas pada satu partisi data menggunakan data tidak seimbang dan menurut (Zhou et al., 2010) meskipun support vector machine tunggal menunjukkan kinerja yang baik dalam klasifikasi, akan tetapi sensitif terhadap pengaturan sampel dan parameter. Oleh karena itu untuk mengatasi masalah tersebut digunakan Least Square Support Vector Machine (LSSVM) yaitu dengan menyelesaikan fungsi kendala berbentuk persamaan linear untuk mendapatkan solusi dari permasalahan quadratic programming.

Penelitian ini mengusulkan metode Ensembel Least Square Support Vector Machine menggunakan Algoritma Boosting dimana algoritma boosting yang digunakan adalah Adaboost. Penelitian ini juga akan menyelidiki diberbagai partisi data untuk melihat kinerja dari metode yang diusulkan.

\section{Metodologi}

\subsection{Support Vector Machine}

Support Vector Machine digunakan untuk memecahkan masalah klasifikasi pola dan sangat cocok digunakan pada data yang dapat dipisahkan secara linear dengan memaksimalkan batas bidang pemisah (Hyperplane) untuk memisahkan data ke dalam dua class pada sebuah ruang fitur (Burges, 1998).
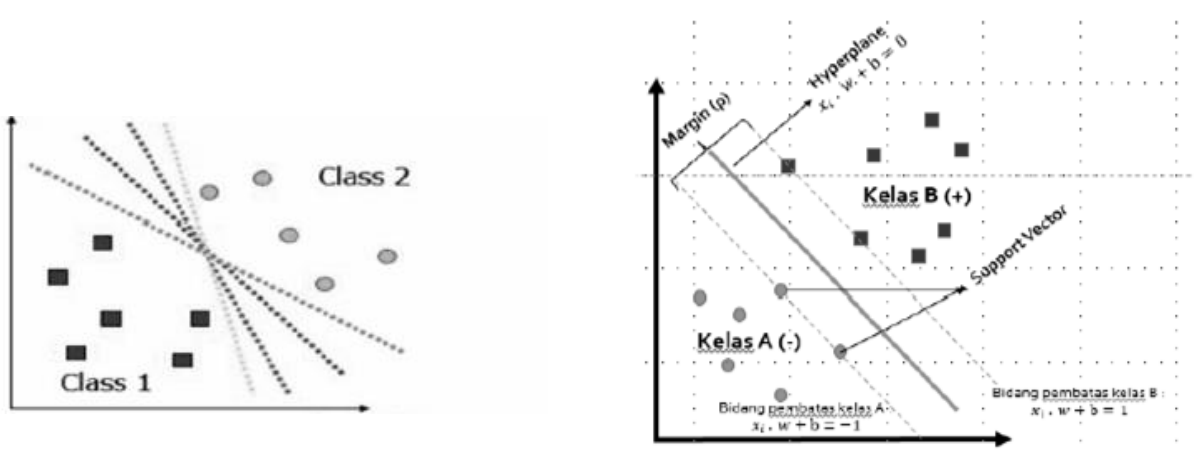

Gambar 1. Konsep Support Vector Machine.

Gambar 1 menunjukkan pilihan hyperplane yang mungkin untuk set data dan bidang pemisah terbaik dengan margin maksimal yang tertelak di antara kedua kelas.

\subsection{Least Square Support Vector Machine}

Least Squares Support Vector Machine merupakan pengembangan SVM yang dipelopori oleh Suykens dan Vandewalle pada tahun 1999 (Suykens \& Vandewalle, 1999). Least Squares Support Vector Machine menghasilkan tingkat error yang lebih rendah dibandingkan dengan Support Vector Machine karena melakukan klasifikasi lanjutan yaitu dengan mengolah kembali data yang salah terklasifikasi menggunakan 
quadratic hyperplane. Bentuk Least Squares Support Vector Machine ditunjukkan dengan fungsi objektif berikut :

$$
\min \frac{1}{2}\|\boldsymbol{w}\|^{2}+\frac{C}{2} \sum_{i=1}^{n} \xi_{i}^{2}
$$

Dengan kendala

$$
y_{i}\left(\varphi\left(\boldsymbol{x}_{\boldsymbol{i}}\right) \cdot \boldsymbol{w}^{T}+b\right)=1-\xi_{i}, k=1,2, \ldots, N
$$

Dimana $\xi$ adalah variabel slack yang menentukan tingkat kesalahan klasifikasi (misclassification) sampel data. $C>O$ adalah parameter yang menentukan besar penalti akibat kesalahan dalam klasifikasi data. $K$ adalah fungsi kernel yang digunakan.

\subsection{Adaptive Boosting (AdaBoost)}

Secara umum algoritma AdaBoost melatih pengklasifikasian dasar secara sekuensial dalam setiap iterasi menggunakan data latih dengan koefisien bobot yang bergantung dari performa pengklasifikasian pada iterasi sebelumnya untuk memberikan bobot yang lebih besar pada data yang salah terklasifikasi (Schapire \& Freund, 2013), (Schwenker, 2013).

langkah-langkah algoritma Adaboost adalah (Freund \& Schapire, 1999):

1. Input: Data pelatihan beserta labelnya $\left\{\left(\boldsymbol{x}_{1}, y_{1}\right), \ldots,\left(\boldsymbol{x}_{\boldsymbol{N}}, y_{N}\right)\right\}$, Component Learn, dan jumlah perputaran $\mathrm{T}$

2. Inisialisasi bobot data pelatihan:

$$
D_{i}^{1}=\frac{1}{N}, i=1, \ldots, N
$$

3. Untuk iterasi $t=1, \ldots, T$

a. Gunakan algoritma Component Learner untuk melatih suatu komponen klasifikasi, $h_{t}$, pada bobot pelatihan.

b. Hitung bobot kesalahan klasifikasi pada $h_{t}$

$$
\epsilon_{t}=\sum_{i=1}^{N}\left(D_{i}^{t}\left(y_{i} \neq h_{t}(x)\right)\right)
$$

Indeks kepercayaan pembelajaran dihitung sebagai:

$$
c_{t}=\frac{1}{2} \ln \left(\frac{\left(1-\epsilon_{t}\right)}{\epsilon_{t}}\right)
$$

c. Perbaharui bobot sampel pelatihan

$$
D_{i}^{t+1}=\frac{D_{i}^{t} \exp \left(c_{t} \times y_{i} \neq y_{i}^{*}\right)}{\sum_{i=1}^{N} D_{i}^{t}}
$$

d. Testing model dengan data uji

4. Keluaran pembelajaran terakhir

Kombinasi semua klasifikasi 
Vol. 1 No. 1 Juli 2020

$$
h_{j}=\operatorname{sign}\left(\sum_{t=1}^{T} c_{t} h_{t}(x)\right)
$$

\subsection{Evaluasi Kinerja}

Evaluasi hasil Kinerja dari setiap klasifikasi di hitung berdasarkan 3 pengukuran yaitu : Accuracy, Sensitivity, dan Specificity berdasarkan nilai True Positive, False Negative, False Positive, dan True Negative.

- True Positive (TP) : Jumlah data yang teridentifikasi sebagai 'Pelanggan Potensial' dan hasil prediksinya 'Pelanggan Potensial'.

- True Negative (TN) : Jumlah data yang teridentifikasi sebagai 'Pelanggan Non-Potensial' dan hasil prediksinya 'Pelanggan Non-Potensial'.

- False Positive (FN) : Jumlah data yang teridentifikasi sebagai 'Pelanggan NonPotensial' tetapi hasil prediksinya 'Pelanggan Potensial'.

- False Negative (FN) : Jumlah data data yang teridentifikasi sebagai 'Pelanggan Potensial' tetapi hasil prediksinya 'Pelanggan Non-Potensial'.

Tabel 1. Confusion Matrix.

\begin{tabular}{lll}
\hline Prediksi & Pelanggan Potensial & $\begin{array}{l}\text { Pelanggan Non- } \\
\text { Potensial }\end{array}$ \\
\hline Pelanggan Potensial & $\begin{array}{l}\text { True Positive } \\
\text { (TP) }\end{array}$ & $\begin{array}{l}\text { False Negative } \\
\text { (FN) }\end{array}$ \\
\hline Pelanggan Non-Potensial & $\begin{array}{l}\text { False Positive } \\
(\mathrm{FP})\end{array}$ & $\begin{array}{l}\text { True Negative } \\
(\mathrm{TN})\end{array}$ \\
\hline
\end{tabular}

$$
\begin{aligned}
& \text { Akurasi }=\frac{T P+T N}{T N+F P+F N+T P} \\
& \text { Sensitivity }=\frac{T P}{T P+F N} \\
& \text { Specificity }=\frac{T N}{T N+F P}
\end{aligned}
$$

\section{Eksperimental}

\subsection{Dataset}

Data yang diolah adalah data bank direct marketing dataset yang dapat diakses melalui University of California at Irvine (UCI) Machine Learning Repository. Data tersebut berasal dari bank Portugal, dari bulan mei 2008 sampai bulan juni 2013.deskripsi dataset ditunjukkan pada Tabel 2 .

Tabel 2. Deskripsi Dataset.

\begin{tabular}{lll}
\hline Atribut & Tipe data & Keterangan \\
\hline Age & Numeric & Umur Pelanggan \\
\hline
\end{tabular}




\begin{tabular}{|c|c|c|}
\hline Atribut & Tipe data & Keterangan \\
\hline Job & $\begin{array}{l}\text { Categorical : } \\
\text { 1. Admin } \\
\text { 2. Blue-collar } \\
\text { 3. Enterpreneur } \\
\text { 4. Housemaid } \\
\text { 5. Management } \\
\text { 6. Retired } \\
\text { 7. Self-employed } \\
\text { 8. Services } \\
\text { 9. Student } \\
\text { 10. Technician } \\
\text { 11. Unemployed } \\
\text { 12. Unknown } \\
\end{array}$ & Tipe Pekerjaan \\
\hline Martial & $\begin{array}{l}\text { Categorical: } \\
\text { 1. Divorced } \\
\text { 2. } \text { Married } \\
\text { 3. Single } \\
\text { 4. } \text { Unknown }\end{array}$ & Status Penikahan \\
\hline Education & $\begin{array}{l}\text { Categorical : } \\
\text { 1. Basic.4y } \\
\text { 2. Basic.6y } \\
\text { 3. Basic.9y } \\
\text { 4. High.school } \\
\text { 5. Illiterate } \\
\text { 6. Professional.course } \\
\text { 7. University.degree } \\
\text { 8. Unknown } \\
\end{array}$ & Tingkat Pendidikan \\
\hline Default & $\begin{array}{l}\text { Categorical : } \\
\begin{array}{l}\text { 1. No } \\
\text { 2. Yes } \\
\text { 3. Unknown }\end{array}\end{array}$ & Apakah memiliki kredit? \\
\hline Housing & $\begin{array}{l}\text { Categorical : } \\
\begin{array}{l}\text { 1. No } \\
\text { 2. Yes } \\
\text { 3. Unknown }\end{array}\end{array}$ & $\begin{array}{l}\text { Apakah memiliki pinjaman } \\
\text { perumahan? }\end{array}$ \\
\hline Loan & $\begin{array}{l}\text { Categorical : } \\
\text { 1. No } \\
\text { 2. Yes } \\
\text { 3. Unknown }\end{array}$ & $\begin{array}{l}\text { Apakah memiliki pinjaman } \\
\text { pribadi ? }\end{array}$ \\
\hline Contact & $\begin{array}{l}\text { Categorical : } \\
\text { 1. Celular } \\
\text { 2. Telephone }\end{array}$ & Dihubungi melalui ? \\
\hline
\end{tabular}


Vol. 1 No. 1 Juli 2020

\begin{tabular}{|c|c|c|}
\hline Atribut & Tipe data & Keterangan \\
\hline Month & $\begin{array}{cl}\text { Categorical : } \\
\text { 1. Jan } \\
\text { 2. Feb } \\
\text { 3. Mar } \\
\text { 4. Apr } \\
\text { 5. May } \\
\text { 6. Jun } \\
\text { 7. Jul } \\
\text { 8. Aug } \\
\text { 9. Sep } \\
\text { 10. Oct } \\
\text { 11. Nov } \\
\text { 12. Dec }\end{array}$ & $\begin{array}{l}\text { bulan terakhir melakukan } \\
\text { kontak dalam setahun? }\end{array}$ \\
\hline Day_of_week & $\begin{array}{c}\text { Categorical : } \\
\begin{array}{cl}\text { 1. } & \text { Mon } \\
\text { 2. } & \text { Tue } \\
\text { 3. } & \text { Wed } \\
\text { 4. } & \text { Thu } \\
\text { 5. } & \text { Fri }\end{array}\end{array}$ & $\begin{array}{l}\text { Hari terakhir melakukan } \\
\text { kontak dalam seminggu ? }\end{array}$ \\
\hline Duration & Numeric & $\begin{array}{l}\text { lama durasi selama } \\
\text { dihubungi. }\end{array}$ \\
\hline Campaign & Numeric & $\begin{array}{l}\text { Jumlah kontak yang } \\
\text { dilakukan selama } \\
\text { pengiklanan untuk nasabah } \\
\text { termasuk kontak terakhir }\end{array}$ \\
\hline Pdays & Numeric & $\begin{array}{l}\text { Selisih hari setelah nasabah } \\
\text { terakhir kali dikontak untuk } \\
\text { pengiklanan sebelumnya }\end{array}$ \\
\hline Previous & Numeric & $\begin{array}{l}\text { Jumlah kontak yang } \\
\text { dilakukan sebelum } \\
\text { pengikanan ini dan untuk } \\
\text { nasabah ini }\end{array}$ \\
\hline Poutcome & $\begin{array}{ll}\text { Categorical : } \\
\begin{array}{ll}\text { 1. } & \text { Failure } \\
\text { 2. } & \text { Nonexistent } \\
\text { 3. } & \text { Success } \\
\end{array}\end{array}$ & $\begin{array}{l}\text { Hasil dari pengiklanan } \\
\text { pemasaran sebelumnya }\end{array}$ \\
\hline $\mathrm{y}$ & $\begin{array}{l}\text { Binary: } \\
\text { 1. Yes } \\
\text { 2. No } \\
\end{array}$ & $\begin{array}{l}\text { Apakah nasabah } \\
\text { berlangganan deposito } \\
\text { berjangka panjang? }\end{array}$ \\
\hline
\end{tabular}

\subsection{Normalisasi Data}

Dari total jumlah data keseluruhan sebanyak 41.188 pelanggan, dinormalisasi menjadi 9.280 untuk menyeimbangkan anatar pelanggan deposito berjangka dan bukan pelanggan deposito berjangka. Jadi data yang diolah sebanyak 4,640 data pelanggan deposito berjangka dan 4,640 data bukan pelanggan deposito berjangka. 
Vol. 1 No. 1 Juli 2020

\subsection{Implementasi}

Fokus dari penelitian ini untuk menerapkan metode ensemble least squares support vector machine menggunakan AdaBoost. Tahapan metode yang diusulkan adalah sebagai berikut :
a. Load Dataset
b. Identifikasi Label Atribut, class dan jumlah data.
c. Menentukan jumlah data latih dan data uji.
d. Membentuk klasifikasi
- Menentukan Nilai Gamma.
- Menentukan Nilai Sigma.
- Inisialisasi Variabel, dan bobot awal.

e. Menentukan jumlah perulangan (Iterasi)

- Menggunakan algoritma component learner (least squares support vector machine) untuk membentuk suatu model klasifikasi.

- Menghitung bobot kesalahan klasifikasi

- Memperbaharui bobot sampel data latih

- Pengujian model dengan data uji

- Hasil dari Pengujian model.

\section{Hasil}

Proses pengujian menggunakan software Matlab untuk melihat kinerja dari metode-metode yang diusulkan. Berdasarkan hasil confusion matrix seperti yang terlihat pada Tabel 3, hasil kinerja dari masing-masing metode ditampilkan pada Tabel 4. Hasil dari total rata-rata yang didapatkan metode ensemble least square support vector machine menggunakan adaboost mendapatkan persentase yang paling tinggi diantara metode support vector machine dan least square support vector machine. Hal ini membuktikan bahwa metode ensemble least square support vector machine menggunakan adaboost lebih baik dibandingkan dengan metode lainnya. Kinerja terbaik dihasilkan ketika partisi data 80:20 yakni $80 \%$ data latih dan $20 \%$ data uji.

Tabel 3. Hasil confusion matrix.

\begin{tabular}{cccccc}
\hline Metode & $\begin{array}{c}\text { Data Latih / } \\
\text { Data Uji \% }\end{array}$ & TP & TN & FP & FN \\
\hline & $10 / 90$ & 4149 & 1943 & 27 & 2233 \\
$20 / 80$ & 3670 & 2272 & 42 & 1440 \\
$30 / 70$ & 3155 & 2054 & 93 & 1194 \\
Support Vector Macine & $40 / 60$ & 2690 & 1622 & 94 & 1162 \\
& $50 / 50$ & 2217 & 1585 & 103 & 735 \\
& $60 / 40$ & 1771 & 1385 & 85 & 471 \\
& $70 / 30$ & 1271 & 1198 & 121 & 194 \\
$80 / 20$ & 908 & 841 & 20 & 87 \\
& $90 / 10$ & 445 & 434 & 19 & 30 \\
\hline
\end{tabular}




\begin{tabular}{lccccc}
\hline Metode & $\begin{array}{c}\text { Data Latih / } \\
\text { Data Uji \% }\end{array}$ & TP & TN & FP & FN \\
\hline & $10 / 90$ & 3924 & 3365 & 252 & 811 \\
& $20 / 80$ & 3556 & 3029 & 156 & 683 \\
& $30 / 70$ & 3069 & 2742 & 179 & 506 \\
Least Square Support & $40 / 60$ & 2642 & 2073 & 142 & 711 \\
Vector Machine & $50 / 50$ & 2152 & 1970 & 168 & 350 \\
& $60 / 40$ & 1756 & 1645 & 100 & 211 \\
& $70 / 30$ & 1260 & 1291 & 132 & 101 \\
& $80 / 20$ & 906 & 852 & 22 & 76 \\
& $90 / 10$ & 442 & 433 & 22 & 31 \\
\hline & $10 / 90$ & 3910 & 3389 & 266 & 787 \\
& $20 / 80$ & 3543 & 3051 & 169 & 661 \\
Ensemble Least Square & $30 / 70$ & 3056 & 2757 & 192 & 491 \\
Support Vector Machine & $40 / 60$ & 2621 & 2125 & 163 & 659 \\
Menggunakan Adaboost & $50 / 50$ & 2124 & 2033 & 196 & 287 \\
& $60 / 40$ & 1743 & 1671 & 113 & 185 \\
& $70 / 30$ & 1260 & 1291 & 132 & 101 \\
& $80 / 20$ & 907 & 859 & 21 & 69 \\
& $90 / 10$ & 443 & 434 & 21 & 30 \\
\hline
\end{tabular}

Tabel 4. Hasil Klasifikasi.

\begin{tabular}{|c|c|c|c|c|c|}
\hline Metode & $\begin{array}{l}\text { Data Latih / } \\
\text { Data Uji \% }\end{array}$ & $\underset{\%}{\text { Accuracy }}$ & $\begin{array}{c}\text { Sensitivity } \\
\%\end{array}$ & $\begin{array}{c}\text { Specificity } \\
\%\end{array}$ & $\begin{array}{c}\text { Rata-Rata } \\
\%\end{array}$ \\
\hline \multirow{9}{*}{ Support Vector Macine } & $10 / 90$ & 72,94 & 65,01 & 98,63 & 78,86 \\
\hline & $20 / 80$ & 80,04 & 71,82 & 98,18 & 83,35 \\
\hline & $30 / 70$ & 80,19 & 72,55 & 95,67 & 82,80 \\
\hline & $40 / 60$ & 77,44 & 69,83 & 94,52 & 80,60 \\
\hline & $50 / 50$ & 81,94 & 75,10 & 93,90 & 83,65 \\
\hline & $60 / 40$ & 85,02 & 78,99 & 94,22 & 86,08 \\
\hline & $70 / 30$ & 88,69 & 86,76 & 90,83 & 88,76 \\
\hline & $80 / 20$ & 94,23 & 91,26 & 97,68 & 94,39 \\
\hline & $90 / 10$ & 94,72 & 93,68 & 95,81 & 94,74 \\
\hline \multirow{9}{*}{$\begin{array}{l}\text { Least Square Support } \\
\text { Vector Machine }\end{array}$} & $10 / 90$ & 87,27 & 82,87 & 93,03 & 87,73 \\
\hline & $20 / 80$ & 88,70 & 83,89 & 95,10 & 89,23 \\
\hline & $30 / 70$ & 89,46 & 85,85 & 93,87 & 89,72 \\
\hline & $40 / 60$ & 84,68 & 78,80 & 93,59 & 85,69 \\
\hline & $50 / 50$ & 88,84 & 86,01 & 92,14 & 89,00 \\
\hline & $60 / 40$ & 91,62 & 89,27 & 94,27 & 91,72 \\
\hline & $70 / 30$ & 91,63 & 92,58 & 90,72 & 91,64 \\
\hline & $80 / 20$ & 94,72 & 92,26 & 97,48 & 94,82 \\
\hline & $90 / 10$ & 94,29 & 93,45 & 95,16 & 94,30 \\
\hline \multirow{5}{*}{$\begin{array}{l}\text { Ensemble Least Square } \\
\text { Support Vector Machine } \\
\text { Menggunakan Adaboost }\end{array}$} & $10 / 90$ & 87,39 & 83,24 & 92,72 & 87,79 \\
\hline & $20 / 80$ & 88,82 & 84,28 & 94,75 & 89,28 \\
\hline & $30 / 70$ & 89,49 & 86,16 & 93,49 & 89,71 \\
\hline & $40 / 60$ & 85,24 & 79,91 & 92,88 & 86,01 \\
\hline & $50 / 50$ & 89,59 & 88,10 & 91,21 & 89,63 \\
\hline
\end{tabular}


Vol. 1 No. 1 Juli 2020

\begin{tabular}{cccccc}
\hline Metode & $\begin{array}{c}\text { Data Latih / } \\
\text { Data Uji } \%\end{array}$ & $\begin{array}{c}\text { Accuracy } \\
\text { \% }\end{array}$ & $\begin{array}{c}\text { Sensitivity } \\
\text { \% }\end{array}$ & $\begin{array}{c}\text { Specificity } \\
\text { \% }\end{array}$ & $\begin{array}{c}\text { Rata-Rata } \\
\text { \% }\end{array}$ \\
\hline $60 / 40$ & 91,97 & 90,40 & 93,67 & 92,01 \\
$70 / 30$ & 91,63 & 92,58 & 90,72 & 91,64 \\
$80 / 20$ & 95,15 & 92,93 & 97,61 & 95,23 \\
$90 / 10$ & 94,50 & 93,66 & 95,38 & 94,52 \\
\hline
\end{tabular}

\section{Kesimpulan}

Dalam penelitian ini diusulkan metode ensemble least squares support vector machine menggunakan AdaBoost untuk mengklasifikasikan pelanggan deposito potensial. Fokus dari penelitian ini adalah meningkatkan kinerja support vector machine yang sensitive terhadap pengaturan sampel dan parameter dengan mengusulkan metode least squares support vector machine. Tetapi, metode least squares support vector machine memiliki masalah pada keacakan sample maka dilakukan pengembangan dengan melakukan teknik ensemble.

Dengan membandingkan hasil kinerja dari metode SVM, LSSVM, dan Ensemble LSSVM menggunakan Adaboost didapatkan hasil bahwa metode yang diusulkan yakni Ensemble LSSVM menggunakan AdaBoost berhasil meningkatkan kinerja dari metode SVM dan LSSVM dengan persentase tingkat accuracy, sensitivity, specivicity masingmasing adalah $95.15 \%, 92.93 \%, 97.61 \%$ dengan total rata-rata hasil klasifikasi sebesar 95.23\%. dapat disimpulkan bahwa metode Ensemble LSSVM berhasil mengatasi kelemahan dari metode SVM dan LSSVM. Untuk kedepannya akan diteliti menggunakan data seimbang.

\section{Daftar Pustaka}

Dedic, N., \& Stanier, C. (2016, December). Measuring the success of changes to existing business intelligence solutions to improve business intelligence reporting. In International Conference on Research and Practical Issues of Enterprise Information Systems (pp. 225-236). Springer, Cham.

Rud, O. P. (2009). Business intelligence success factors: tools for aligning your business in the global economy (Vol. 18). John Wiley \& Sons.

Moro, S., Laureano, R., \& Cortez, P. (2011). Using data mining for bank direct marketing: An application of the crisp-dm methodology. In Proceedings of European Simulation and Modelling Conference-ESM'2011 (pp. 117-121). EUROSIS-ETI.

Elsalamony, H. A., \& Elsayad, A. M. (2013). Bank direct marketing based on neural network and C5. 0 Models. Int. J. Eng. Adv. Technol. IJEAT, 2(6).

Elsalamony, H. A. (2014). Bank direct marketing analysis of data mining techniques. International Journal of Computer Applications, 85(7), 12-22.

Vajiramedhin, C., \& Suebsing, A. (2014). Feature selection with data balancing for prediction of bank telemarketing. Applied Mathematical Sciences, 8(114), 56675672.

Abbas, S. (2015). Deposit subscribe prediction using data mining techniques based Real marketing dataset. arXiv preprint arXiv:1503.04344. 
Zhuang, Q. R., Yao, Y. W., \& Liu, O. (2018). Application of data mining in term deposit marketing. In Proceedings of the International MultiConference of Engineers and Computer Scientists (Vol. 2).

Parlar, T. (2017). Using data mining techniques for detecting the important features of the bank direct marketing data. International journal of economics and financial issues, 7(2), 692.

Ruangthong, P., \& Jaiyen, S. (2015, July). Bank direct marketing analysis of asymmetric information based on machine learning. In 2015 12th International Joint Conference on Computer Science and Software Engineering (JCSSE) (pp. 93-96). IEEE.

Grzonka, D., Suchacka, G., \& Borowik, B. (2016). Application of selected supervised classification methods to bank marketing campaign. Information Systems in Management, 5(1), 36-48.

Lawi, A., Velayaty, A. A., \& Zainuddin, Z. (2017, August). On identifying potential direct marketing consumers using adaptive boosted support vector machine. In 2017 4th International Conference on Computer Applications and Information Processing Technology (CAIPT) (pp. 1-4). IEEE.

Zhou, L., Lai, K. K., \& Yu, L. (2010). Least squares support vector machines ensemble models for credit scoring. Expert Systems with Applications, 37(1), 127-133.

Burges, C. J. (1998). A tutorial on support vector machines for pattern recognition. Data mining and knowledge discovery, 2(2), 121-167.

Suykens, J. A., \& Vandewalle, J. (1999). Least squares support vector machine classifiers. Neural processing letters, 9(3), 293-300.

Schapire, R. E., \& Freund, Y. (2013). Boosting: Foundations and algorithms. Kybernetes. Schwenker, F. (2013). Ensemble methods: Foundations and algorithms [book review]. IEEE Computational Intelligence Magazine, 8(1), 77-79. 